\title{
Correction to: Fusulinoids from the Carboniferous-Permian transition beds from the Abadeh Region (Sanandaj-Sirjan Zone, Iran)
}

\author{
Shirin Fassihi ${ }^{1} \cdot$ Masatoshi Sone $^{1} \cdot$ Vachik Hairapetian $^{2} \cdot$ Fariba Shirezadeh Esfahani $^{3}$
}

Published online: 1 June 2019

○) Springer-Verlag GmbH Germany, part of Springer Nature 2019

\section{Correction to: Carbonates Evaporites}

https://doi.org/10.1007/s13146-017-0390-1

The original version of this article unfortunately contained a mistake. Some labels are missing in the figure 3 . The corrected Figure 3 is included in the next page.

The original article has been corrected.

The original article can be found online at https://doi.org/10.1007/ s13146-017-0390-1.

Masatoshi Sone

Masatoshi.sone@gmail.com

1 Department of Geology, Faculty of Science, University of Malaya, 50603 Kuala Lumpur, Malaysia

2 Department of Geology, Islamic Azad University, Isfahan (Khorasgan) Branch, PO Box 81595-158, Isfahan, Iran

3 Department of Geology, Faculty of Basic Sciences, Islamic Azad University of Tehran, North Branch, 1667934783 Tehran, Iran 
Fig. 3 Geological map of the Abadeh area showing the location of the Banarizeh section. The base map was modified from the Izadkhast Map, 1:100,000 series sheet, no. 6453 (Hamzehpour and Nazari 1998)

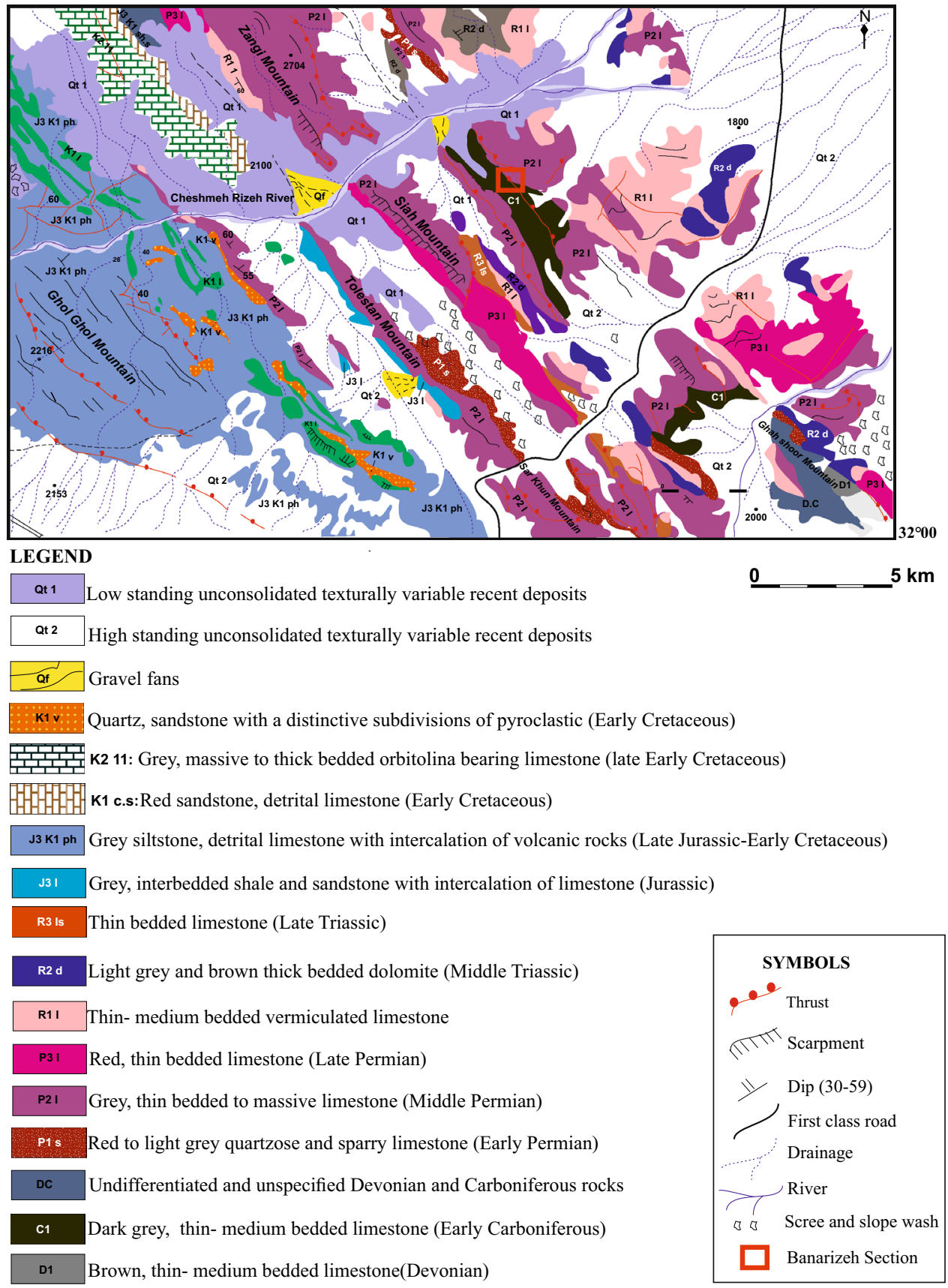

Publisher's Note Springer Nature remains neutral with regard to jurisdictional claims in published maps and institutional affiliations. 